\title{
PROCESSO CIVILIZADOR: APONTAMENTOS METODOLÓGICOS NA HISTORIOGRAFIA DA EDUCAÇÃO FÍSICA
}

\author{
DR. EDIVALDO GÓIS JUNIOR \\ Faculdade de Educação Física, Universidade Estadual \\ de Campinas (Campinas - São Paulo - Brasil) \\ E-mail: edivaldo.gois@pq.cnpq.br
}

DR. HUGO RODOLFO LOVISOLO

Faculdade de Comunicação Social, Universidade do Estado do Rio de Janeiro (Rio de Janeiro - Rio de Janeiro - Brasil)

E-mail: lovisolo@globo.com

\author{
DRA. VILMA LENÍ NISTA-PICCOLO \\ Programa de Pós-Graduação em Educação, Universidade \\ Federal do Triângulo Mineiro (Uberaba - Minas Gerais - Brasil) \\ E-mail: vilma@nista.com.br
}

\begin{abstract}
RESUMO
Este artigo tem como objetivo analisar a utilização do modelo elisiano em problemas de pesquisa no campo da História da Educação Física. Para isso, analisaram-se as características teóricas do processo civilizador de Elias. Posteriormente, testamos as explicações da teoria do processo civilizador na historiografia da Educação Física. Conclui-se que a teoria do processo civilizador deve ser aplicada de forma mais criteriosa neste campo de investigação.
\end{abstract}

PALAVRAS-CHAVE: Educação física; História; Metodologia da história; Historiografia. 
O objetivo deste estudo consiste na análise teórica do Processo civilizador no campo da historiografia da Educação Física. Descreveremos o uso metodológico da teoria do processo civilizador na pesquisa histórica neste campo. Inicialmente, apresentaremos uma revisão sobre a teoria do processo civilizador, e em um segundo momento, abordaremos os critérios para a utilização da teoria na investigação histórica. Finalmente, observaremos o uso do modelo elisiano no campo da historiografia da Educação Física Brasileira. Para isto, em termos metodológicos, levantamos todos os trabalhos completos publicados em 2009, no XI Congresso Nacional de História do Esporte, Educação Física, Lazer e Dança, e definimos como critério de inclusão na amostra, apenas os textos que tivessem Norbert Elias como referência. Posteriormente, analisamos se os trabalhos se caracterizavam como historiografia, e finalmente, discutimos a pertinência do uso metodológico de Elias nos textos.

Seguindo a orientação de Carlos Antonio Aguirre Rojas (1998), delimitamos esta análise de maneira disciplinar no campo da História. Embora admitimos que o uso de Elias extrapole a historiografia, tendo papel relevante nas Ciências Sociais. Com esta delimitação, optamos pela análise dos dois volumes do Processo Civilizador por representar, segundo Aguirre Rojas ( 1998), a principal obra historiográfica de Norbert Elias.

\section{PROCESSO CIVILIZADOR}

O problema de pesquisa de Norbert Elias nos dois volumes do Processo Civilizador consiste em compreender o curso das transformações gerais da sociedade, que ocorreram na longa duração e na direção de um processo de civilização. Esse quadro, para o autor, contribui para uma transformação da afetividade do comportamento e experiência humanos, e para o controle de emoções individuais por imposição externa e autocontrole (ELIAS, 1994a).

Para compreender o modelo elisiano, temos que ter em mente a relação entre a estrutura das personalidades individuais e a dinâmica de determinada sociedade. Assim, a pressão das regras de uma sociedade é reproduzida nos indivíduos como controle das emoções, ambas as dimensões são incorporadas como habitus. (LANDINI, 2006)

Ao contrário da ideia de caráter nacional que caracterizava uma personalidade coletiva (LEITE, 1976) de maneira estática, o termo habitus é dinâmico. Para compreender essa dinâmica, Elias busca descrever suas forças motrizes, ou seja, por que existe a mudança. Então aponta que as dinâmicas sociais produzem 
comportamentos que, em segundo momento, são internalizados, influenciando a personalidade individual (LANDINI, 2006). Como podemos perceber, o modelo elisiano não é centrado no indivíduo, e também contraria a noção dicotômica entre social e individual. Em seu modelo o indivíduo é analisado a partir do conceito de configuração, no qual a personalidade individual é aberta e mutável, mas livre e autônoma apenas em certo grau, já que nas relações com outras pessoas, o indivíduo torna-se interdependente (LANDINI, 2006).

No primeiro volume do Processo Civilizador, Elias concentra-se em demonstrar empiricamente se existiram mudanças de comportamento, nas emoções, nas estruturas de controle na longa duração, retratando essas mudanças desde o cavaleiro medieval ao burguês do século XVIII e XIX, sobretudo, na Inglaterra, França e Alemanha. Defende que essas diferentes sociedades europeias caminharam, cada uma a seu modo, na mesma direção (ELIAS, 1994a).

Depois de demonstrar essas transformações nas emoções e estruturas de controle humano, no segundo volume, debruça-se sobre uma segunda questão: essas mudanças na personalidade humana teriam relação com as mudanças políticas e sociais, com a formação dos Estados Nacionais na Europa? (ELIAS, 1994b). Para o autor, esse processo aumentou o grau de diferenciação e integração dessas sociedades europeias, à medida que elas prolongaram as cadeias de interdependência entre os grupos sociais e consolidaram os controles estatais, como o monopólio, por exemplo, da violência.

Com este enfoque teórico e empírico, Elias estaria concentrado em entender mudanças estruturais de longo prazo. (ELIAS, 1994a).

Elias argumenta que no período medieval, os cavaleiros deveriam amar ou odiar, defender seus interesses, não temer a morte. Quem não agisse dessa forma não teria espaço na sociedade. Ao contrário disso, no Renascimento, a autonomia dos cavaleiros medievais é substituída pela dependência de um poder centralizado na monarquia. Desse modo, a regra agora é se relacionar na corte, controlar as emoções, entrar em um jogo político de interdependência. Para Elias:

\footnotetext{
Esta descrição ajuda-nos a ver com mais clareza algo que, até agora, só foi dito em termos gerais, isto é, a conexão entre estrutura social e estrutura da personalidade. Nessa sociedade não havia poder central suficientemente forte para obrigar as pessoas a se controlarem. Mas se nesta região ou naquela o poder de uma autoridade central crescia, se em uma área maior ou menor as pessoas eram forçadas a viver em paz entre si, a modelação das emoções e os padrões da economia dos instintos lentamente mudavam. (ELIAS, 1994a, p. 199).
}

Esse argumento torna-se mais afinado e aprofundado no segundo volume, no qual Elias demonstra a relação entre essa estrutura de personalidade e o advento do Absolutismo. 
Então a consequência desses fatos através de configurações sociais levou a uma centralização do poder, representada pelo monopólio da violência por parte dos Estados Nacionais na Europa. Sem outras possibilidades, setores da nobreza passaram a fazer parte dos serviços burocráticos dos reis, aumentando sua dependência em relação ao poder central.

Essa dependência aproximou todos da vida de corte, onde os hábitos mais rudes, os costumes mais autênticos e desinibidos da sociedade medieval, são suavizados, polidos e civilizados (ELIAS, 1994b). Em seus termos:

A pressão da vida de corte, a disputa pelo favor do príncipe ou do 'grande' e depois, em termos gerais, a necessidade de distinguir-se dos outros e de lutar por oportunidades através de meios relativamente pacíficos (como a intriga e a diplomacia), impuseram uma tutela dos afetos, uma autodisciplina e um autocontrole, uma racionalidade distintiva de corte [...] (ELIAS, 1994b, p. 18)

O aumento do controle estatal e do monopólio da violência, com o advento do absolutismo, criou, por conseguinte, no aspecto do indivíduo, um autocontrole, uma disciplina, regulada pelos medos. Para Elias, nenhuma sociedade pode sobreviver sem canalizar as pulsões e emoções do indivíduo. Para exercer controle, as pessoas impõem normas de conduta umas às outras, e essas limitações geram os medos (ELIAS, 1994b).

A partir do século XVIII, com a ascensão das classes burguesas, as normas de conduta burguesa se amalgamaram com as da sociedade de corte, e foram disseminadas mais amplamente nos estratos sociais emergentes, dando prosseguimento ao Processo Civilizador. Antes dos protestos, em relação à condição de civilização, Elias deixa claro que o processo ainda está em andamento, não está acabado.

Aliás, o processo inclusive passa por crises, explosões (des)civilizadoras, que invertem provisoriamente o processo civilizador. Para Eric Dunning e Stephen Mennel (1998), uma vez que o processo civilizador está incompleto, pode sofrer abalos, e explodir em manifestações públicas de violência. Enfim, este breve relato sobre a sociologia de Elias vislumbra como na longa duração, gostaríamos de enfatizar, longa duração, uma configuração inicial, ou seja, medieval, se transforma em outra, representada pelo absolutismo e, ao mesmo tempo, indica uma transformação na personalidade dos indivíduos. E, agora, perguntamos como esta teoria pode nos auxiliar no desvelar de um problema de pesquisa histórica?

A questão que parece central é a do poder da teoria para tratar (refinar, esclarecer e desvendar, entre outros sentidos possíveis) dos problemas no campo da história da Educação Física e Esporte, não de um modo auxiliar ou ilustrativo, porém, enquanto teoria propriamente dita. 
Primeiramente, entendemos que a teoria do processo de civilizador e das configurações sociais, quando adotadas como métodos de uma historiografia, não devem estar na periferia, e sim, no centro dos problemas de pesquisa. Não podemos conceber a citação do processo civilizador como um complemento, um detalhe que agrega brilho ou lustre ao trabalho. Caso seja adotada a teoria, ela estará no centro do estudo e relacionada diretamente com o problema de pesquisa. Perguntamos: a potente teoria do processo civilizador, em termos metodológicos, aplica-se a qualquer problema de pesquisa? Acreditamos que não, pelos seguintes motivos:

I) O próprio Norbert Elias nos dá a primeira pista. Quando em 1968, Elias escreve o prefácio de uma reedição do Processo Civilizador, ele demonstra uma mágoa com a sociologia da época, que não se interessava por processos sociais de longo prazo que traziam consigo a ideia de mudança. Ao contrário disto, os sociólogos contemporâneos a Elias, no fim dos anos sessenta, preferiam estudar sociedades em um suposto equilíbrio e repouso, execrando a ideia de mudança e desenvolvimento. Em seus termos: "[...] ocorreu uma reação extremamente violenta contra o tipo de teoria sociológica preocupada com processos sociais de longo prazo" (ELIAS, 1994a, p. 224). Esse fato, segundo Elias (1994a), criou uma série de preconceitos em relação a sua teoria, por ser entendida na ideia de evolução. Fundamentalmente o interesse e aplicação do processo civilizador se sustentam no estudo da mudança no longo prazo, o que não se aplicava na sociologia de meados do século $X X$, interessada no imutável. Por isso, entendemos que esta concepção fundamental do estudo da mudança no longo prazo deve estar inerente a qualquer estudo historiográfico que se coloca em termos metodológicos em uma perspectiva figuracionista, ou que baseia-se na verificação do processo civilizador. Sem o estudo da mudança de configuração, não existe teoria do processo civilizador.

2) Além da questão da mudança, a teoria do processo civilizador só pode ser demonstrada empiricamente por Elias em estudos históricos de longa duração. Como conseguiríamos realizar tal verificação ou aproximação da teoria com dados empíricos de objetos de pesquisa em pequenos recortes historiográficos, sem compará-los à longa duração? Se não estudamos a longa duração, ou a comparamos com a curta duração, não aplicamos a teoria.

3) $\bigcirc$ processo civilizador é construído a partir da teoria das configurações sociais, ou seja, como uma configuração inicial de poder político, econômico, social se transforma em outra, e concomitantemente, são transformadas as estruturas de personalidade dos indivíduos. Se não estudamos a relação entre estrutura política, poder e a personalidade dos indivíduos em sua conduta, não estudamos o processo civilizador.

Enfim, para se estudar o processo civilizador relacionado a um problema de pesquisa, é preciso considerar a mudança, a periodização de longo prazo e a relação entre estrutura social e personalidade humana. 
No campo da historiografia da Educação Física, principalmente entre os pesquisadores brasileiros, existe uma forte influência da teoria do Processo Civilizador na análise dos dados empíricos.

Em 2009, por ocasião do XI Congresso Nacional de História do Esporte, Educação Física, Lazer e Dança, foram publicados 86 trabalhos completos, destes I 8 trabalhos utilizaram Norbert Elias como referência.

Esta forte incidência do autor no campo da historiografia da Educação Física brasileira se explica por dois fatores: o valor que Norbert Elias e Eric Dunning deram ao Esporte como problema de pesquisa da Sociologia. Para Dias (20 I0), este pioneirismo chamou a atenção de pesquisadores da área de Educação Física, principalmente na Inglaterra e Holanda (DIAS, 20 I0), e em segundo lugar no Brasil, pela influência do chamado Grupo de Campinas.

O Grupo de Campinas se estabelece no início dos anos de 1990, a partir dos orientandos do Prof. Ademir Gebara, na Universidade Estadual de Campinas. Historiador e professor de Educação Física, Gebara foi docente da FEF-UNICAMP, onde orientou muitas dissertações e teses de doutorado. Para promover e divulgar a produção da historiografia da Educação Física, o grupo foi pioneiro na organização de um congresso disciplinar no campo. Paulatinamente o Grupo de Campinas aproximou-se também de sociólogos, sobretudo a partir do III Encontro Nacional, realizado em 1995, em Curitiba. Com o decorrer da década de 1990, Gebara formou mais mestres e doutores, que se disseminaram pelo país. Os marcos teóricos do grupo eram os estudos de história e sociologia do esporte com aporte em de Norbert Elias.

Com isso, a influência do grupo cresceu, sobretudo nos congressos que tematizavam a história da Educação Física, e desse modo, o uso do modelo elisiano foi bastante presente no país.

Este uso, muitas vezes, respeita os critérios metodológicos que levantamos anteriormente, quais sejam: I) a observação das mudanças de configuração, 2) a observação dos objetos na longa duração, ou na comparação com a longa duração 3) observação da relação entre estrutura social e personalidade humana. Contudo, em outras oportunidades, os estudos utilizam superficialmente a teoria do processo civilizador, bem como a observação empírica dos dados não é criteriosa.

Defendemos que a utilização da teoria do processo civilizador é pertinente, desde que observado a especificidade do objeto de estudo. Por exemplo, pesquisadores como Eric Dunning mostraram que os estudos da história e sociologia do esporte podem ser analisados à luz do modelo elisiano (MARCHI JÚNIOR, 2005; PRONI, 1998). Em A busca da excitação (ELIAS; DUNNING, 1992), Dunnig e Elias defendem 
que atividades esportivas vivenciadas como propostas de lazer configuram-se como estratégias em que se opera uma substituição mimética da violência, ocasionando algum grau de liberação do autocontrole imposto pelo processo civilizador.

Entendemos que o modelo de interpretação e análise dos dados a partir da observação de configurações pode ser muito útil também no campo da Educação Física, como por exemplo, no estudo da adoção da Ginástica Francesa no Brasil, e de alguns métodos ginásticos europeus na relação com os hábitos burgueses e consolidação do urbano e industrial no país.

Contudo, entendemos que o modelo elisiano pouco pode contribuir para a análise de outros objetos, por isso, não é uma teoria totalizante, ou um modelo universal para a análise de qualquer problemática. Para a aplicação do modelo elisiano na historiografia há de se observar alguns critérios, como os levantados anteriormente.

Com isso, fazemos a crítica ao exagero, à aproximação teórica sem o devido cuidado metodológico. Para apontarmos como o sociólogo Norbert Elias é citado na área de História da Educação Física, analisamos os trabalhos completos publicados no XI Congresso Nacional de História do Esporte, Educação Física, Lazer e Dança:

Foram publicados 86 trabalhos, destes I 8 faziam referência a Norbert Elias.

Primeiramente, dos 18 trabalhos, apenas 10 trabalhos foram observados como textos de história, com problema, delimitação, objetivos, método e fontes concernentes ao campo específico. Os 8 trabalhos excluídos da análise tinham problemas de pesquisa atrelados à Sociologia do Esporte e Educação Física.

Então, observamos como os 10 trabalhos utilizaram conceitos de Elias pertinentes à historiografia, como configuração, longa duração e habitus.

Em relação ao critério sobre a observação das mudanças de configuração, dos 10 trabalhos, 3 trabalhos fizeram esta discussão. Sobre a observação dos objetos na longa duração, ou na comparação com a longa duração, dos 10 trabalhos, os mesmos 3 trabalhos tematizaram, ou compararam a longa duração com a curta duração. Em relação às estruturas sociais e a personalidade humana constituíam um habitus, apenas 2 trabalhos analisaram estas relações. A maioria dos trabalhos, 7 , fazia referência superficial ou secundária ao sociólogo alemão.

Medeiros e Godoy (2009), ao analisarem o uso da sociologia de Norbert Elias na Revista Brasileira de Ciências do Esporte, chegaram a resultado semelhante: dos 12 trabalhos publicados com o referencial de Elias, apenas 5 discutiam mais de um conceito sociológico do autor, como habitus, configuração, longa duração. Os demais citavam Elias de forma genérica, de maneira pontual.

Os usos e abusos do modelo elisiano vem provocando críticas por parte de pesquisadores na área de Ciências Sociais, como Giulianotti (2002), e também no campo da Educação Física, como Dias (20 l 0). As críticas consistem principalmente 
na tese de eurocentrismo, pois seus dados empíricos e teorias se estabelecem neste contexto. $\bigcirc$ modelo elisiano também é acusado de naturalizar fatos sociais, pois estão presentes termos da Biologia, Psicologia e Física. Contudo, o foco de nossa crítica não é a Sociologia de Elias, mas sim, a utilização metodológica de seus conceitos na historiografia.

\section{CONSIDERAÇÕES FINAIS}

Os estudos de Elias ganharam maior repercussão na área de Educação Física por influência de artigos que tematizaram o Esporte à luz do modelo eliasiano, sobretudo na Inglaterra. Por exemplo: Eric Dunning (DUNNING; MENNEL, 1998; DUNNING; SHEARD, 1979; DUNNING; MURPHY; WILLIAMS, I988; DUNNING, I999; MURPHY; WILLIAMS; DUNNING, 1990), em diversos estudos, Sport Matters: Sociological Studies of Sport, Violence and Civilisation; The roots of football hooliganism; Barbarians, gentlemen and players: a sociological study of the development of rugby football, Football on Trial: Spectator Violence and Development in the Football World, sustentam a tese de que o Esporte, tanto na efetiva prática, como em sua espetacularização através dos veículos de comunicação de massa, formação de torcidas, e consequentes explosões de violência, é explicado a partir da formação do estado e monopólio da violência, e concomitantemente, com a formação de personalidades humanas e mecanismos de autocontrole.

Em outras palavras, a necessidade da inculcação de um autocontrole gerou também nos indivíduos outra necessidade, qual seja a liberação pública dos mecanismos de autocontrole, levando a uma prazerosa sensação de liberdade (GEBARA, 2000). Essas emoções podem se transformar em explosões de violência, como por exemplo, na violência dos torcedores, no hooliganismo. Desse modo, coletivamente, os indivíduos buscam no esporte, vivenciar emoções fortes, liberdade, poder.

A partir destas problematizações, pesquisadores brasileiros como Vanderlei Marchi Júnior (2005), Marcelo Proni (1998), Ricardo de Figueiredo Lucena (1998) utilizaram com propriedade a contribuição de Elias para estudar o fenômeno esportivo, do lazer, e da Educação Física.

Contudo, o que este trabalho demonstra é que a contribuição de Norbert Elias é utilizada de forma superficial na maioria dos textos produzidos no campo da história da Educação Física. Ainda colocamos em pauta a discussão sobre a utilização de sua contribuição para todos os problemas de pesquisa no campo da História da Educação Física sem critério.

Nestes pontos reside nossa crítica, na historiografia da Educação Física que interpreta os dados empíricos à luz do modelo elisiano de maneira linear, ou seja, 
verificando a existência do processo civilizador, e desconsiderando suas reações, suas oposições. Se a análise fosse realizada neste enfoque, tendo como orientação ações e reações, propostas antagônicas, críticas e reformulações, substituiríamos uma história linear por uma pendular. O movimento pendular dificultaria consideravelmente estabelecer a tendência do processo histórico.

Se observarmos a história na longa duração, o modelo elisiano contribui para a análise empírica da historiografia da Educação Física, pois as manifestações corporais são sistematizadas, se desenvolveram e influenciaram outras culturas. Verificamos essas evidências na crescente racionalização de suas práticas, nos espaços normatizados, na utilização de aparelhos artificiais, mas esta análise ocorre na longa duração. Quando estudamos o contexto de determinados recortes históricos, nos deparamos com reações ao processo civilizador, que o caracterizam de maneira não-linear, ou seja, pendular.

Consideramos, portanto, que a historiografia da Educação Física pode e deve estudar este interessante autor, bem como seus seguidores, como Eric Dunning. Contudo, sua utilização deve ser mais criteriosa. Devemos entender que certas ferramentas são mais úteis em contextos específicos do que outras, pois senão, cairemos no risco das teorias totalizantes, que se colocam como solução para qualquer problema de pesquisa. Por conseguinte, transformar-nos-emos em verificadores, que buscarão a qualquer custo qualquer aproximação, por mais superficial que seja, entre teoria e empiria.

\section{Civiling Process: Methodological Points in Historiography of Physical Education}

ABSTRACT: This study has as goal to analyze the use of Elias ' model on the History studies. For that, it accomplished a discussion on the theoretical and empiric characteristics of the civilizing process of Elias. Afterwards, we analyzed the theory of the civilizing process in History studies, specifically, in Physical Education. In conclusion, the civiling process should be studied carefully in the field of History of Physical Education.

KEYWORDS: Physical education; history; history methods; historiography.

\section{Proceso Civilizador: apontes metodológicos}

en la historiografía de la Educación Física

RESUMEN: Este artículo pretende analizar el uso del modelo de Norbert Elias en problemas de investigación en el campo de la historia. Para esto, se analizó los aspectos teóricos y empíricos del proceso civilizador de Elías. Posteriormente, se estudió las explicaciones de la teoría del proceso civilizador en la comprensión de los problemas de la investigación histórica, 
en particular, en el Educación Fisica. Concluimos que la teoría del proceso civilizador debe aplicarse con criterio en el campo de la Historia de la Educación Física.

PALABRAS CLAVE: Educación Física, historia, metodología de la historia, historiografía.

\section{REFERÊNCIAS}

AGUIRRE ROJAS, C. A. Norbert Elias: historiador y crítico de la modernidad. Diálogos, Maringá, v. 2, n. I, p. I-27. 1998.

CONGRESSO NACIONAL DE HISTÓRIA DO ESPORTE, EDUCAÇÃO FÍSICA, LAZERE DANÇA. I I., 2009, Viçosa. Anais... Viçosa: Universidade Federal de Viçosa, 2009. v. I.

DIAS, C. A Sociologia figuracional e os estudos do esporte. Revista Brasileira de Ciências do Esporte, Campinas, v. 31, n. 2, p. 155-169, jan./mar. 2010.

DUNNING, E.; MENNEL, S. Elias on germany, Nazism and the Holocaust: on the balance between 'civilizing' and 'decivilizing' trends in the social development in Western Europe. British Journal of Sociology, London, v. 49, n. 3, p. 339-358, sept. 1998.

DUNNING, E.; SHEARD, K. Barbarians, gentlemen and players: a sociological study of the development of rugby football. Oxford: Martin Robertson, 1979.

DUNNING, E.; MURPHY, P.; WILLIAMS, J. The roots of football hooliganism. London: Routledge, 1988.

DUNNING, E. Sport matters: sociological studies of sport, violence and civilization. London: Taylor \& Francis, 1999.

ELIAS, N.; DUNNING, E. A busca da excitação. Lisboa: Difel, 1992.

ELIAS, N. O processo civilizador: uma história dos costumes. Rio de Janeiro: Jorge Zahar, I994a.

ELIAS, N. O processo civilizador: formação do estado e civilização. Rio de Janeiro: Jorge Zahar, 1994b.

GEBARA, A. Norbert Elias e a teoria do processo civilizador: contribuição para a análise e a pesquisa no campo do lazer. In: BRUHNS, H. T. (Org.). Temas sobre o lazer. Campinas: Autores Associados, 2000. p. 33-46.

GIULIANOTTI, R. Sociologia do futebol. São Paulo: Nova Alexandria, 2002.

LANDINI, T. S. A Sociologia de Norbert Elias. Revista Brasileira de Informação Bibliográfica em Ciências Sociais, São Paulo, n. 6I, p. 91-108, 2006.

LEITE, D. M. Caráter nacional brasileiro: história de uma ideologia. 3. ed. São Paulo: Pioneira, 1976.

LUCENA, R. F. Jogo e esporte: uma conversa com Elias e Huizinga. Conexões, Campinas, v. I, n. I, p. 18-27, 1998. 
MARCHI JUNIOR, W. O processo de ressignificação do voleibol a partir da inserção da televisão no campo esportivo. Revista Brasileira de Ciências do Esporte, Campinas, v. 26, n. 2, p. I49-162, jan./mar. 2005.

MEDEIROS, C. C. C.; GODOY, L. As referências de Pierre Bourdieu e Norbert Elias na Revista Brasileira de Ciências do Esporte: mapeando tendências de apropriação e produção de conhecimento na área da Educação Física (1979-2007). Revista Brasileira de Ciências do Esporte, Campinas, v. 30, n. 2, p.199-214, jan./mar. 2009.

MURPHY, P.; WILLIAMS, J.; DUNNING, E. Football on trial: spectator violence and development in the football world. London: Routledge, 1990.

PRONI, M. W. Esporte-espetáculo e futebol-empresa. 1998. 262 f. Tese (Doutorado em Educação Física) - Faculdade de Educação Física, Universidade Estadual de Campinas, Campinas, 1998.

Recebido em: 10 mar. 2010 Aprovado em: 24 ago. 2010

Endereço para correspondência:

Edivaldo Góis Junior Departamento de Educação Física e Humanidades Av. Érico Veríssimo, 701.

Cidade Universitária

Campinas-SP CEP | 3083-85 | 